\title{
Prevalence and Characerizaion of Salmonella pullorum from Day Old Chicks Distributed to Farms in Akwa Ibom State, Nigeria
}

\author{
Maduike Chiehiura Onwubiko Ezeibe', Aniefiok Emerson Udom1, \\ Obiageli Favour Onyeachonam ${ }^{1}$, Ijeoma Joy Ogbonna1, Clara Amaka Akpan', \\ Obianuju Nkiruka Okoroafor ${ }^{2}$ \\ ${ }^{1}$ College of Veterinary Medicine, Michael Okpara University of Agriculture, Umudike, Nigeria \\ ${ }^{2}$ Department of Veterinary Medicine, University of Nigeria, Nsukka, Nigeria \\ Email: uju.okoroa for@unn.edu.ng
}

How to cite this paper: Ezeibe, M.C.O., Udom, A.E., Onyeachonam, O.F., Ogbonna, I.J., Akpan, C.A. and Okoroafor, O.N. (2019) Prevalence and Characerizaion of Salmonella pullorum from Day Old Chicks Distributed to Farms in Akwa Ibom State, Nigeria. Health, 11, 1573-1580.

https://doi.org/10.4236/health.2019.1112118

Received: August 22, 2019

Accepted: December 8, 2019

Published: December 11, 2019

Copyright $\odot 2019$ by author(s) and Scientific Research Publishing Inc. This work is licensed under the Creative Commons Attribution International License (CC BY 4.0).

http://creativecommons.org/licenses/by/4.0/

CC) (i) Open Access

\begin{abstract}
To investigate sources of Salmonella pullorum infections that cause frequent outbreaks of bacillary white diarrhea in poultry and sporadic human food poisoning in Nigeria, prevalence of the infection among day-old-chicks in Akwa-Ibom State, south-south Nigeria, was studied. From each depot/hatchery, 30 day-old chicks were randomly selected for their livers, spleens, kidneys, hearts, yolk sacs and intestines which were processed and cultured on appropriate bacterial media. Colonies that grew from the specimens were characterized based on their morphologies, staining characteristics, biochemical reactions and cultural characteristics. Gram positive isolates that were: short, plum shaped, rods, non-spore forming and non-capsulated were identified as Salmonella species. Motility test and biochemical tests on the Salmonella colonies identified those that were $S$. pullorum. Five percent of chicks being distributed in Akwa-Ibom State, Nigeria were infected with $S$. pullorum, the agent of, bacillary white diarrhea (which causes high mortality in chicks) and food poisoning in man.
\end{abstract}

\section{Keywords}

Bacillary White Diarrhea, Food Poisoning

\section{Introduction}

Poultry is the largest livestock industry in the world. It is very important in the economy of most countries because the industry is affordable and chicks are easily managed and fast-growing, compared to other livestock. Poultry industry is 
an important source of food and income to the world [1]. Poultry meat and eggs are major sources of animal protein in many developing countries, including Nigeria, because the meat and eggs are affordable and generally acceptable [2]. Nigeria's poultry industry is expanding but it is facing many challenges such as outbreaks of diseases (Avian influenza, Salmonellosis especially pullorum disease, Colibacillosis) and financial crisis [3].

Pullorum disease is an acute systemic or chronic disease of young poultry of ages between 2 to 4 weeks and of other avian species with high morbidity and high mortality [1]. It is a bacterial infection, almost exclusively a septicemic disease of young chicks, caused by Salmonella entrica subspecies entrica serovar pullorum [1] [4]. The bacterium may also be associated with disease in turkey poults and other avian species.

In older chickens, Salmonella pullorum infection may be subclinical and manifest only as reduced egg production, poor fertility and poor hatchability. The bacterium is closely related to other Salmonella species, such as, Salmonella gallinarum, Salmonella enteritidis, Salmonella typhi and Salmonella Dublin, which are grouped under sero-group D. They are classified under the family: Enterobacteriaceae [1] [5].

Salmonella pullorum and Salmonella gallinarum are indistinguishable by normal sero-typing. Both belong to sero-group $D$ and possess $O$ antigen 1, 9, 12 and are non-flagellated. They are generally regarded as biotypes of the same serovar [4].

Chickens are natural hosts of Salmonella pullorum [6] [7], other birds such as turkeys, quail, guinea fowl, pheasants, goose, parrots, sparrows and ring neck doves can be infected [8] [9].

Salmonella pullorum is the etiologic agent of bacillary white disease otherwise called pullorum disease [4]. In Nigeria and all over the world, pullorum disease is said to be of high incidence [4] [10] [11] [12]. Infected layers may become chronic carriers and transmit the organism to their embryos through the eggs [13]. Egg transmission may result from contamination of ovum following ovulation or localization of the bacterium in the ovum before ovulation [4] [6]. Chicks can also be infected through chick-to-chick contact, bird-to-bird contact, cannibalism of infected carcasses, wound contamination, fecal contamination of water or feed [4] [13]. Wild birds, rats and insects also act as vectors in transmission of Salmonella pullorum in poultry and other aviaries [12] [14]. Contamination between birds may also occur by introduction of infected sub clinically sick birds into the production chain. Morbidity and mortality are usually high within 2 - 3 weeks of age. Chicks and poults may develop nonspecific signs like depression, weakness, somnolence, loss of appetite, droopy wings, dehydration and ruffled feathers [15]. Necropsy findings in young chicks that die of pullorum disease may include, unabsorbed yolk sacs, peritonitis, grayish nodules in the liver, heart, spleen, lungs, gizzard and intestines [5] [6] [13] [15]. The liver, kidneys and spleen are often congested and enlarged, with dilatation of subcutaneous blood vessels [16] The ceca may be enlarged and contain firm cheesy materials 
called cecal cores [5] [16].

Apart from high morbidity and mortality which $S$. pullorum causes in poultry chicks and other avian species, it causes poor hatchability and infertility and reduced egg production in layers [1] [6] It is also a zoonosis [15] that causes "food poisoning" in man [17].

So, the study was designed to isolate Salmonella pullorum from day-old chicks being distributed to farms in Nigeria and to determine prevalence of the infection among chicks in order to aid development of effective control measures for the disease.

\section{Materials and Methods}

Four chick depots and two hatcheries in Uyo, Abak and Ikot Ekpene (in Akwa-Ibom State, Nigeria) were used for the study. From each depot/hatchery, thirty (30) day-old chicks were randomly selected. From each sacrificed chick, the internal organs (liver, spleen, kidney, heart, yolk sac and intestines) were collected in a specimen bottle that contained sterile enrichment medium (selenite F broth). They were taken to the Laboratory (within 24 hours of collection) for isolation of Salmonella pullorum. The specimens were macerated, placed in a sample bottle with sterile selenite $\mathrm{F}$ broth and incubated at $37^{\circ} \mathrm{C}$ for 24 hours, as recommended by OIE [13].

For presumptive isolation of $S$. pullorum, a loop-full of inoculum from each of the inoculated enrichment broth was sub-inoculated on brilliant green agar (BGA), MacConkey agar (MCA) and on Salmonella-Shigella agar (SSA) respectively. The plates were incubated at $37^{\circ} \mathrm{C}$ for 24 hours and were checked for growths of characteristic Salmonella colonies [11]. Colonies with Salmonella characteristics: small, smooth and colorless on MCA or small, pale, colorless on BGA or smooth, opaque or translucent, round with black centers on SSA were picked, inoculated onto nutrients agar (NA) and incubated at $37^{\circ} \mathrm{C}$ for 24 hours. Thereafter, they were stored in a refrigerator at $4^{\circ} \mathrm{C}$.

For further studies, a loop-full of each isolate was placed on a glass slide with a drop of normal saline, mixed, smeared and air dried. Crystal violet was added. After 30 seconds, the smear was washed with distilled sterile water and iodine solution dropped on the slide. The iodine solution was washed after 30 seconds and acetone was added and finally saffarin solution was added to the smear and it was washed off after 30 seconds using running water. The glass slide was observed under the microscope using $\times 10$ objective lens. Isolates that were Gram negative, short, plum shaped, rods, non-spore forming and non-capsulated were taken as suggestive of Salmonella species [13] [14].

Motility test was performed by the hanging drop slide method described by Hossain et al. [16], to differentiate motile salmonellae from non-motile ones. Before performing the hanging drop slide test, a pure culture of each of the isolates was allowed to grow in nutrient broth. One drop of the cultural broth was placed on a cover-slip which was placed inversely over a glass slide supported by plastacin to make hanging drop preparation. The hanging drop preparation was 
carefully examined under 40-power objective of a compound microscope for motility. Non motile isolates were taken to be either Salmonella pullorum or Salmonella gallinarum and were further investigated by serological tests. Such isolates suspected to be Salmonella pullorum or Salmonella gallinarum were serologically tested for confirmation by the procedure recommended by OIE [13]. The commercial salmonella polyvalent "O" antiserum was also used for the slide agglutination test. Pure colonies of the isolates from nutrient agar plates were used for the test. Before testing with the sera, the isolates were tested with sterile saline to eliminate auto-agglutinable strains. Samples taken from a single colony of the isolate using sterile wire loop was transferred onto glass slide and mixed with a drop of sterile saline. The slide was rocked gently for 30 - 60 seconds and observed for agglutination with the aid of magnifying glass. No clumping of the bacterium into distinct units was interpreted as no agglutination. Non-agglutinable isolates were further tested as follows; Swab from a single colony was dispensed in a drop of Salmonella polyvalent "O" antiserum to obtain a homogenous and turbid suspension. After gentle rocking for 30 - 60 seconds, the reaction was observed with the aid of magnifying glass for agglutination. Positive reaction was considered as Salmonella species.

Isolates were heavily inoculated in bijou bottles containing $3 \mathrm{ml}$ sterile urea agar with phenol red as an indicator and incubated at $37^{\circ} \mathrm{C}$ for 24 hours. Pink color was read as urease positive while absence of pink color was read as urease negative according to Cheesbrough [18]. Isolates that tested urease negative were preserved for further investigations as suggested by Cowan and Steel [19].

Indole test was also performed on the isolates as described by Cheesbrough [18]. Isolates that were urease negative were inoculated into $2 \mathrm{ml}$ of sterile peptone water in bijou bottles and incubated aerobically for 48 hours. Then $0.5 \mathrm{ml}$ of Kovac's reagent was added, the bottle was shaken thoroughly and the samples examined after one minute. Red colored layer indicated indole positive while lack of red color was read as indole negative. Methyl red test was conducted on the isolates as described by Hossain et al. [20]. Isolates were inoculated into 0.5 $\mathrm{ml}$ sterile glucose phosphate broth in bijou bottles and incubated at $37^{\circ} \mathrm{C}$ for 24 hours. A drop of methyl red solution was added to each bottle. Appearance of a bright red color was read as methyl red positive while yellow or orange color was read as negative. Triple sugar iron agar (TSIA) was used to detect lactose, saccharose and dextrose fermenters and to determine ability of the isolates to produce hydrogen sulphide $\left(\mathrm{H}_{2} \mathrm{~S}\right)$. The isolates were heavily seeded with a platinum needle over slants and stabbed into the butt of the tubes containing TSI agar. The platinum needle was pulled back and the rest of the inocula streaked on the slant of the agar surface. After incubating the TSI agar tubes at $37^{\circ} \mathrm{C}$ for 24 hours, the tubes were examined for changes in the slants or the butts or broth. Appearance of pinkish slants with yellow butt was recorded as positive reaction while black butt was taken to indicate $\mathrm{H}_{2} \mathrm{~S}$ production. Sugar fermentation test was carried out as described by Hossain et al. [20] and Cheesbrough [18].

Samples from urease negative colonies were inoculated into phenol red lactose 
broth and incubated at $37^{\circ} \mathrm{C}$ for 24 hours. Colonies that retained the red color were classified as Salmonella species. Samples were taken from urease negative colonies and inoculated into phenol red dulcitol broth and incubated at $37^{\circ} \mathrm{C}$ for 24 hours. Those that retained the red color were taken as confirmation of Salmonella pullorum. Prevalence of Salmonella pullorum among the day-old chicks was expressed in percentages (\%).

\section{Results}

Out of the 180 chicks sampled from 4 depots/hatcheries in Akwa Ibom State, Nigeria, Salmonella pullorum was isolated from 9 (5\%). On nutrient agar (NA), the growth were small, circular and colorless. On MacConkey agar (MCA), they were small, smooth and colorless. On Brillant green agar (BGA), the S. pullorum colonies were circular, pinkish, lactose-non fermenting while on Salmonella-Shigella agar (SSA) the colonies were smooth, opaque, translucent, colorless and round with black centers. All the isolates were none motile, Gram negative, short rods, pinkish, none spore forming and none capsulated. They fermented glucose, aga-lactose and mannitol with acid and gas production but did not ferment lactose, maltose and dulcitol and were indole negative, urease negative and methyl red positive. On triple sugar iron (TSI) agar, the isolates produced hydrogen sulphide $\left(\mathrm{H}_{2} \mathrm{~S}\right)$, alkaline slant and acid butt.

Cultural characteristics, morphology, motility and staining characteristics of Salmonella pullorum isolates from hatcheries and chick-depots in Akwa-Ibom State, Nigeria, are as in Table 1 while their biochemical characteristics are as in Table 2.

Table 1. Cultural, morphology, motility and staining characteristics of Salmonella pullorum isolates from chicks being distributed in Akwa Ibom State, Nigeria.

\begin{tabular}{|c|c|}
\hline Tests & Characteristics/Reactions \\
\hline \multicolumn{2}{|l|}{ Cultural media } \\
\hline Nutrient agar & Small, circular and colourless \\
\hline MacConkey agar & Small, smooth and colourless \\
\hline Brillant green agar & Circular, pinkish, lactose-non fermenting \\
\hline Salmonella-Shigella agar & $\begin{array}{c}\text { Smooth, opaque, translucent. Colourless and round } \\
\text { with black center (varies) }\end{array}$ \\
\hline \multicolumn{2}{|l|}{ Motility } \\
\hline Hanging drop method & Non motile \\
\hline Gram staining & Gram negative \\
\hline Cell shape & Short rod \\
\hline Colour & Pinkish \\
\hline Spore & None \\
\hline Capsule & None \\
\hline
\end{tabular}


Table 2. Biochemical characteristics of Salmonella pullorum isolates from chicks being distributed in Akwa Ibom State, Nigeria.

\begin{tabular}{cc}
\hline Tests & Reactions \\
\hline Urease & Negative \\
TSI & Alkaline slant, acid butt with $\mathrm{H}_{2} \mathrm{~S}$ production (black colour) \\
Methyl red & Positive \\
Indole & Negative \\
\hline Sugar fermentation & Negative \\
\hline Sucrose & Positive (acid and gas production) \\
Glucose & Negative \\
Dulcitol & Negative \\
Lactose & Negative \\
Maltose & Positive (acid and gas production) \\
Mannitol & Positive (acid and gas production) \\
Galactose &
\end{tabular}

\section{Discussion}

The finding that chicks which were only a few hours old were already infected with Salmonella pullorum supports the report that the infection could be transmitted from infected hens through their eggs to chicks which hatch from the eggs [13]. The 5\% prevalence got among day-old chicks distributed in Akwa Ibom State, Nigeria is evidence of high prevalence of the infection among poultry in the country.

Most chicks being distributed from chick-depots in Akwa-Ibom state come from hatcheries located in states in South-west Nigeria (Ogun and Oyo States). It is possible that the infections came from those hatcheries. This suggests that the problem may be widespread in the country as all states being serviced by the hatcheries may have the problem. It may not be a local problem but same for all the states.

The results which show that Salmonella pullorum is widely distributed among chicks agree with Netsan et al. [21] who reported high prevalence of Salmonella pullorum in Nigeria. High prevalence of this fastidious bacterium which can be transmitted to several other avian species and can survive in the environment for several years may be contributing to high morbidity, high mortality and low productivity often experienced in poultry in Nigeria. This widespread of $S$. pullorum infection in Nigeria is a threat to National and individuals' economies.

The results also agree with the reports of Kumar et al [15] and Tadele et al [22] that hatcheries play important roles in spreading Salmonella pullorum infections. The finding is a serious threat to the poultry industry and to public health in Nigeria. Proper farm management practices, including improved bio-security measures are recommended for prevention and control of this infection. 


\section{Authors' Contributions}

The authors collaborated for the research. Author MCOE designed the experiments and drafted the manuscript while author AEU conducted the laboratory work. Authors OFO, IJO and CAA analyzed the data while author ONO processed the manuscript for publication. All the authors read the draft-manuscript.

\section{Conflicts of Interest}

The authors declare no conflicts of interest regarding the publication of this paper.

\section{References}

[1] Markos, T. and Abdela N. (2016). Epidemiology and Economic Importance of Pullorum Disease in Poultry: A Review. Global Veterinaria, 17, 228-237.

[2] Bettridge, J.M., Lunch, S.E., Brena, M.C., Melese, K., Dessie, T., Terfa, Z.G., Desta, T.T., Hanotte, S., Kaiser, P., Wigley, P. and Chistley, R.M. (2014) Infection-Interactions in Ethiopia Village Chickens. Preventive Veterinary Medicine, 117, 320-322. https://doi.org/10.1016/j.prevetmed.2014.07.002

[3] Food and Agricultural Organization (FAO) (2008) Assessment of the Nigerian Poultry Market Chain to Improve Bio-Security, Rome.

[4] Barrow, P.A. and Neto, O.C. (2011) Pullorum Disease and Fowl Typhoid-New Thoughts on Old Diseases: A Review. Avian Pathology, 40, 1-13. https://doi.org/10.1080/03079457.2010.542575

[5] Dalai, N., Shekhar, S., Padhy, A., Praveen, P.K. and Sahu, A.R. (2015) Salmonellosis-A Potential Threat to Poultry: A Mini Review. Journal of Cell and Tissue Research, 15, 5209-5213.

[6] Shivaprasad, H.L. (2000) Fowl Typhoid and Pullorum Disease. Revue Scientifique et Technique, 19, 405-424. https://doi.org/10.20506/rst.19.2.1222

[7] Center for Food Security and Public Health (2009) Fowl Typhoid and Pullorum Disease. Iowa State University College of Veterinary Medicine, Ames, IA, 1-4.

[8] Spickler, A.R., Roth, J.A. and Dvorak, G. (2010) Emerging and Exotic Disease of Animals. 4th Edition, CFSPH Iowa State University, Ames, IA, 165-168.

[9] Tunca, R., Toplu, N., Kirkan, S., Avci, H., Andogan, A., Epikmen, E.T. and Tekbiyik, S. (2012) Pathomorphological, Immunohistochemical and Bacteriological Findings in Budgerigars (Melopsittacus undulatus) Naturally Infected with S. gallinarum. Avian Pathology, 41, 203-209. https://doi.org/10.1080/03079457.2012.663076

[10] Salihu, A.E., Onwuliri, F.C. and Mawak, J.D. (2014) The Carrier Rate of Salmonella gallinarum in Free Range Chickens in Nasarawa State, Nigeria. International Journal of Advanced Biological and Biomedical Research, 1, 114-122.

[11] Salihu, A.E., Onwuliri, F.C. and Mawak, J.D. (2014) Antimicrobial Resistance Profiles of Salmonella gallinarum Isolates from Free-Range Chickens in Nasarawa State, Nigeria. International Journal of Bacteriology Research, 2, 19-27.

[12] Agada, G.O.A., Abdullahi, I.O., Aminu, M., Odugbo, M., Chollom, S.C., Kumbish, P.R. and Okwori, A.E.J. (2014) Prevalence and Antibiotic Resistance Profile of Salmonella Isolates from Commercial Poultry and Poultry Farm-Handlers in Jos, Plateau State, Nigeria. British Microbiology Research Journal, 4, 462-479. https://doi.org/10.9734/BMRJ/2014/5872

[13] Office International Des Epizootics (OIE) (2012) Fowl Typhoid and Pullorum Dis- 
ease. OIE Terrestrial Manual, Chapter 2.3.11.

[14] Saha, A.K., Sufian, M.A., Hossain, M.I. and Hossain, M.M. (2012) Salmonellosis in Layer Chickens: Pathological Features and Isolation of Bacteria from Ovories and Inner Content of Laid Eggs. Journal of the Bangladesh Agricultural University, 10, 61-67. https://doi.org/10.3329/jbau.v10i1.12095

[15] Kumari, D., Mishra, S.K. and Lather, D. (2013) Pathomicrobial Studies on Salmonella gallinarum Infection in Broiler Chickens. Veterinary World, 6, 725-729. https://doi.org/10.14202/vetworld.2013.725-729

[16] Nazir, S., Kamil, S.A., Darzi, M.M., Mir, M.S., Nazir, K. and Amare, A. (2012) Pathology of Spontaneously Occuring salmonellosis in Commercial Broiler Chickens of Kashmir Valley. The Journal of World's Poultry Research, 2, 63-69.

[17] Haider, M.G., Chowdhury, E.H., Sharif, S.M.K. and Hossain, M.M. (2013) Pathogenesis of Pullorum Disease in Chickens by Local Isolate of Salmonella pullorum in Bangladesh. SAARC Journal of Agriculture, 11, 1-16. https://doi.org/10.3329/sja.v11i2.18398

[18] Cheesbrough, M. (2010) District Laboratory Practice in Tropical Countries. 2nd Edition, Cambridge University Press, Cambridge, United Kingdom.

[19] Cowan, S.T. and Steel, K.J. (2002) Manual for the Identification of Medical Bacteria. 2nd Edition, Cambridge University Press, Cambridge, 51-120.

[20] Hossain, M.S., Chowdhury, E.H., Islam, M.M., Haider, M.G. and Hossain, M.M. (2006) Avian Salmonellosis Infection: Isolation and Identification of Organisms and Histopathological Study. Bangladesh Journal of Veterinary Medicine, 4, 7-12. https://doi.org/10.3329/bjvm.v4i1.1518

[21] Nesa, M.K., Khan, M.S.R and Alam, M. (2011) Isolation and Characterization of Salmonella Serovars from Diarrhoeic Stool Samples of Human. Bangladesh Journal of Veterinary Medicine, 9, 85-93. https://doi.org/10.3329/bjvm.v9i1.11218

[22] Tadele, G., Asrade, B., Bayleyegn, G. and Ali, M. (2014) Seroprevalence of Fowl Typhoid and Pullorum Disease from Apparently Healthy Chickens in Eastern Ethiopia. Journal of Veterinary Science \& Technology, 5, 2157. https://doi.org/10.4172/2157-7579.1000156 